\title{
Editorial: Mechanisms of neuroinflammation and inflammatory neurodegeneration in acute brain injury
}

\author{
Arthur Liesz ${ }^{1,2 *}$ and Christoph Kleinschnitz ${ }^{3}$ \\ ${ }^{1}$ Institute for Stroke and Dementia Research, Klinikum der Universität München, Munich, Germany, ${ }^{2}$ Munich Cluster for \\ Systems Neurology (SyNergy), Munich, Germany, ${ }^{3}$ Department of Neurology, University Hospital Würzburg, Würzburg, \\ Germany
}

Keywords: stroke, intracerebral hemorrhage, traumatic brain injury, neuroinflammation, leukocytes

\section{OPEN ACCESS}

Edited and reviewed by: Egidio D'Angelo,

University of Pavia, Italy

*Correspondence: Arthur Liesz, arthur.liesz@med.uni-muenchen.de

Received: 12 May 2015 Accepted: 21 July 2015 Published: 05 August 2015

Citation: Liesz A and Kleinschnitz C (2015) Editorial: Mechanisms of neuroinflammation and inflammatory neurodegeneration in acute brain injury. Front. Cell. Neurosci. 9:300. doi: 10.3389/fncel.2015.00300
The current research topic and eBook "Mechanisms of neuroinflammation and inflammatory neurodegeneration in acute brain injury" was initiated as a reaction to the rapidly expanding literature on inflammatory mechanisms in the pathophysiology of acute brain injuries. The scope of this compilation of reviews, opinion, and original research articles was to give a broad overview of the diverse cellular compartments and mechanisms involved in the inflammatory response to brain tissue injury.

Although a specific aspect of the pathophysiology of acute brain injuries, the immune system interacts in highly complex as well as diverse mechanisms with the damaged brain.

On one side acute brain lesions, such as brain ischemia, hemorrhage or traumatic injury, induce a local neuroinflammatory reaction, wherein microglial cells represent the local immune cells (Benakis et al., 2015; Lourbopoulos et al., 2015). This local inflammatory response has a major impact on outcome with differential effects during the phases of post-stroke lesion evolution and recovery (Shichita et al., 2014). Intriguingly, besides abundant evidence on poststroke neuroinflammation immunological mechanisms similar mechanisms are also observed in traumatic brain injuries (Schwarzmaier and Plesnila, 2014), intracerebral hemorrhage (Mracsko and Veltkamp, 2014) and even ethanol-induced neurotoxicity (Alfonso-Loeches et al., 2014; Sokolowski et al., 2014) or direct application of exogenous pathogens (Gullo et al., 2014) with functional consequences for neuronal outcome. Moreover, Gauberti et al. (2014) present an overview on state-of-the-art molecular magnetic resonance imaging of neuroinflammatory markers. In recent years also the molecular pathways and effector molecules of inflammationinduced neurotoxicity after acute injuries have been investigated in great detail: Murray et al. (2015) describe in their review the prominent role of the pro-inflammatory cytokine IL-1, Orsini et al. (2014) give an overview on the complement system in neuroinflammation, while AlbertWeissenberger et al. (2014a) focus on the contribution of the kallikrein-kinin system in traumatic brain injury and Zhao et al. (2014) review the current knowledge on programed death-1/programed death ligand signaling. In addition to the activation of local inflammatory pathways in the injured brain, invasion of peripheral immune cells to the brain is a critical step in secondary neuroinflammation. Gelderblom et al. (2014) review the role of gdT cells as a pro-inflammatory invariant $\mathrm{T}$ cell subpopulation recruited to the injured brain. In contrast, Urra et al. (2014) discuss potential mechanisms of antigen-specific autoimmunity after acute brain injury. In addition, the original research article by Kim et al. (2014) underlines that the cellular immune response to ischemic brain injury might differ substantially between commonly used mouse strains. 
In addition to an overview and discussion of basic mechanisms and involved pathways in secondary neuroinflammation after acute brain injury, our research topic also contains several reviews and original articles on novel therapeutic approaches to modulate the immune response. Rissiek et al. (2014) introduce nanobodies as a novel tool for targeting neuroinflammation. Brunkhorst et al. (2014) provide an overview on the promising approach of blocking cellular neuroinflammation with Fingolimod. Bodhankar et al. (2014) review the current literature on targeting the PDL1 and PD-L2 pathways. The original article by Mouihate (2014) reports a novel role for hormonal replacement therapy in neuroinflammation and the original article by

\section{References}

Albert-Weissenberger, C., Mencl, S., Hopp, S., Kleinschnitz, C., and Sirén, A.-L. (2014a). Role of the kallikrein-kinin system in traumatic brain injury. Front. Cell. Neurosci. 8:345. doi: 10.3389/fncel.2014.00345

Albert-Weissenberger, C., Mencl, S., Schuhmann, M. K., Salur, I., Göb, E., Langhauser, F., et al. (2014b). C1-Inhibitor protects from focal brain trauma in a cortical cryolesion mice model by reducing thrombo-inflammation. Front. Cell. Neurosci. 8:269. doi: 10.3389/fncel.2014.00269

Alfonso-Loeches, S., Ureña-Peralta, J. R., Morillo-Bargues, M. J., OliverDe La Cruz, J., and Guerri, C. (2014). Role of mitochondria ROS generation in ethanol-induced NLRP3 inflammasome activation and cell death in astroglial cells. Front. Cell. Neurosci. 8:216. doi: 10.3389/fncel.2014. 00216

Benakis, C., Garcia-Bonilla, L., Iadecola, C., and Anrather, J. (2015). The role of microglia and myeloid immune cells in acute cerebral ischemia. Front. Cell. Neurosci. 8:461. doi: 10.3389/fncel.2014.00461

Bodhankar, S., Chen, Y., Lapato, A., Vandenbark, A. A., Murphy, S. J., and Offner, H. (2014). Targeting immune co-stimulatory effects of PD-L1 and PD-L2 might represent an effective therapeutic strategy in stroke. Front. Cell. Neurosci. 8:228. doi: 10.3389/fncel.2014.00228

Brunkhorst, R., Vutukuri, R., and Pfeilschifter, W. (2014). Fingolimod for the treatment of neurological diseases-state of play and future perspectives. Front. Cell. Neurosci. 8:283. doi: 10.3389/fncel.2014.00283

Dotson, A. L., Zhu, W., Libal, N., Alkayed, N. J., and Offner, H. (2014). Different immunological mechanisms govern protection from experimental stroke in young and older mice with recombinant TCR ligand therapy. Front. Cell. Neurosci. 8:284. doi: 10.3389/fncel.2014.00284

Gauberti, M., Montagne, A., Quenault, A., and Vivien, D. (2014). Molecular magnetic resonance imaging of brain-immune interactions. Front. Cell. Neurosci. 8:389. doi: 10.3389/fncel.2014.00389

Gelderblom, M., Arunachalam, P., and Magnus, T. (2014). $\gamma \delta \mathrm{T}$ cells as early sensors of tissue damage and mediators of secondary neurodegeneration. Front. Cell. Neurosci. 8:368. doi: 10.3389/fncel.2014.00368

Gullo, F., Amadeo, A., Donvito, G., Lecchi, M., Costa, B., Constanti, A., et al. (2014). Atypical "seizure-like" activity in cortical reverberating networks in vitro can be caused by LPS-induced inflammation: a multi-electrode array study from a hundred neurons. Front. Cell. Neurosci. 8:361. doi: $10.3389 /$ fncel.2014.00361

Kim, H. A., Whittle, S. C., Lee, S., Chu, H. X., Zhang, S. R., Wei, Z., et al. (2014). Brain immune cell composition and functional outcome after cerebral ischemia: comparison of two mouse strains. Front. Cell. Neurosci. 8:365. doi: $10.3389 /$ fncel.2014.00365

Lourbopoulos, A., Ertürk, A., and Hellal, F. (2015). Microglia in action: how aging and injury can change the brain's guardians. Front. Cell. Neurosci. 9:54. doi: $10.3389 /$ fncel.2015.00054
Albert-Weissenberger et al. (2014b) the use of C1-inhibitors in a cortical cryolesion model. Dotson et al. (2014) have tested the use of recombinant TCR ligand with differential effects in young and old mice (see also commentary by Pennypacker, 2014).

In summary this research topic gathered contributions from the leading laboratories working in the field of secondary neuroinflammation after brain injury with nearly 100 authors from 4 continents. We are confident that this compilation covers most established and emerging research questions in this specific research field and presents an up-to-date overview on inflammatory mechanisms and drug targets in acute brain injuries.

Mouihate, A. (2014). TLR4-mediated brain inflammation halts neurogenesis: impact of hormonal replacement therapy. Front. Cell. Neurosci. 8:146. doi: $10.3389 /$ fncel.2014.00146

Mracsko, E., and Veltkamp, R. (2014). Neuroinflammation after intracerebral hemorrhage. Front. Cell. Neurosci. 8:388. doi: 10.3389/fncel.2014.00388

Murray, K. N., Parry-Jones, A. R., and Allan, S. M. (2015). Interleukin-1 and acute brain injury. Front. Cell. Neurosci. 9:18. doi: 10.3389/fncel.2015.00018

Orsini, F., De Blasio, D., Zangari, R., Zanier, E. R., and De Simoni, M.G. (2014). Versatility of the complement system in neuroinflammation, neurodegeneration and brain homeostasis. Front. Cell. Neurosci. 8:380. doi: $10.3389 /$ fncel.2014.00380

Pennypacker, K. R. (2014). Commentary: different immunological mechanisms govern protection from experimental stroke in young and older mice with recombinant TCR ligand therapy. Front. Cell. Neurosci. 8:339. doi: 10.3389/fncel.2014.00339

Rissiek, B., Koch-Nolte, F., and Magnus, T. (2014). Nanobodies as modulators of inflammation: potential applications for acute brain injury. Front. Cell. Neurosci. 8:344. doi: 10.3389/fncel.2014.00344

Schwarzmaier, S. M., and Plesnila, N. (2014). Contributions of the immune system to the pathophysiology of traumatic brain injury-evidence by intravital microscopy. Front. Cell. Neurosci. 8:358. doi: 10.3389/fncel.2014.00358

Shichita, T., Ito, M., and Yoshimura, A. (2014). Post-ischemic inflammation regulates neural damage and protection. Front. Cell. Neurosci. 8:319. doi: $10.3389 /$ fncel.2014.00319

Sokolowski, J. D., Chabanon-Hicks, C. N., Han, C. Z., Heffron, D. S., and Mandell, J. W. (2014). Fractalkine is a "find-me" signal released by neurons undergoing ethanol-induced apoptosis. Front. Cell. Neurosci. 8:360. doi: 10.3389/fncel.2014.00360

Urra, X., Miró, F., Chamorro, A., and Planas, A. M. (2014). Antigen-specific immune reactions to ischemic stroke. Front. Cell. Neurosci. 8:278. doi: $10.3389 /$ fncel.2014.00278

Zhao, S., Li, F., Leak, R. K., Chen, J., and Hu, X. (2014). Regulation of neuroinflammation through programed death-1/programed death ligand signaling in neurological disorders. Front. Cell. Neurosci. 8:271. doi: 10.3389/fncel.2014.00271

Conflict of Interest Statement: The authors declare that the research was conducted in the absence of any commercial or financial relationships that could be construed as a potential conflict of interest.

Copyright $\odot 2015$ Liesz and Kleinschnitz. This is an open-access article distributed under the terms of the Creative Commons Attribution License (CC BY). The use, distribution or reproduction in other forums is permitted, provided the original author(s) or licensor are credited and that the original publication in this journal is cited, in accordance with accepted academic practice. No use, distribution or reproduction is permitted which does not comply with these terms. 